\title{
Thriving in Graduate School as an International Student: How to Combat the Hidden Costs and Barriers
}

\author{
Melanie Sayuri Dominguez ${ }^{* \dagger}$ and Seo-young Silvia Kim ${ }^{\ddagger}$ \\ ${ }^{+}$University of New Mexico \\ $\ddagger$ American University
}

January 9, 2022

\begin{abstract}
International students face various hidden costs that pose potential barriers to thriving in graduate school. In this chapter, we lay out several types of hidden costs: (1) higher expenses and time needed for the international status, (2) adjusting to living in a new country and its cultural differences, and (3) biases and racism. We emphasize that the success and happiness of international students depend on the department and the committee's understanding of these hidden costs. We highlight strategies that international students can take as well as point-by-point advice for the supporters of international students.
\end{abstract}

\section{Word Count: 3,730}

Being an international student ${ }^{1}$ in a U.S. graduate school is an opportunity that can bring joy as well as rich, in-depth knowledge to the discipline. But it also comes with a surprisingly large number of barriers that, ex-ante, students may not be fully aware of. Based on our experiences as and interactions with international students, this paper will briefly discuss hidden costs and barriers that international students may face, what the department can do to combat them, and how students can better prepare themselves for studying in the U.S. to thrive and succeed.

\section{Time and Money}

There is a surprising amount of money and time costs involved to obtain and maintain international status. It usually starts from the application status-English language tests such as TOEFL

${ }^{*}$ Melanie is a Ph.D. candidate in Political Science and a Doctoral Fellow at the Center for Social Policy at the University of New Mexico and is the corresponding author (msonntag@unm.edu). Kim is an Assistant Professor of Government at American University. We thank Jan Zilinsky, Hyun Min Park, John Kuk, Eunbin Chung, Minseon Park, Hyun Jin Kim, Shiro Kuriwaki, Zhao Li, Le Bao, and Cherie Strachan for comments.

${ }^{1}$ The focus of our discussion are international graduate students on F-1 or J-1 visas studying in the United States. 
iBT are incredibly costly. ${ }^{2}$ Applications fees are often higher for international students with fewer possibilities of fee waivers. There is the visa application fee to the consulate, and the I-901 SEVIS Fee to the U.S. Immigration and Customs Enforcement (ICE) is also hefty. ${ }^{3}$ Students will also be required to go to the embassy or consulate for an interview to get the visa. These additional steps that international students have to complete are on top of general admissions requirements that graduate students have to complete to apply to programs, including the Graduate Record Examination (GRE). ${ }^{4}$

Once students move to the prospective student status after having overcome the hurdle of applications, they must submit proof of finances to address the requirements of the U.S. immigration laws. The difficulty of securing sufficient funds depends on the stipend paid and the estimated tuition and living costs. Note that overseas shipping is also a significant cost moving to the U.S.

If University housing is not accessible, larger sums of deposits are needed to secure housing and credit cards because the student does not have an SSN or a tax identification number-i.e., without a credit history. ${ }^{5}$ This locks the flexibly usable funds in the early period of adjustment. Note that this is, more often than not, complicated further because the first paycheck only arrives after a full month or more after the semester start date in the U.S., despite the fact that per current rules, international students can arrive as early as 30 days before their program's start date. Given that students arrive weeks in advance to facilitate the adjustment, this means that they must survive on existing funds for up to two months in the U.S., burning through-a rough estimate- of at least $\$ 3,000$ to $\$ 5,000$ until the first stipend arrives. ${ }^{6}$

Having settled into the U.S., going back for a visit home is costly in time, energy, and money, and often much more than what domestic students would face. That your support network is so far away is already quite a burden, and depending on the country, door-to-door travel one way may involve a full twenty-four hours, with thousands of dollars necessary on the round trip air travel. On top of that, travel restrictions may lead to students not being able to visit home even if they have the financial resources and the time. Although less common in political science, some graduate students also face a limit on how many days they can be away from work. Given this, many students do not go home unless strictly necessary, which leads to a lack of social support compared to those who can afford to see their loved ones more often.

Another cost is visa renewals. The F-1 student visa can only be renewed outside the U.S. For certain nationalities (for example, Chinese students), the validity of the visa is shorter, requiring

\footnotetext{
${ }^{2}$ Check https:/ /www.ets.org/toefl for the most up to date pricing.

${ }^{3}$ Their website lays out the prices: https://www.ice.gov/sevis/i901

${ }^{4}$ More information on the GRE can be found on their website: https://www.ets.org/gre

${ }^{5}$ There are credit cards specifically created for international students in the U.S. Schools may also provide partnerships with banks or credit unions for comparable services. The credit limit for such first cards is typically low, but it allows students to begin building a credit history in the U.S.

${ }^{6}$ Note that these numbers vary and depend hugely on the city where the college is located, rent prices, cost of living, inflation, and other potential expenses. For an accurate estimate, we recommend students ask multiple graduate students in their prospective program.
} 
more frequent travel, draining the resources from their academic performance.

Finally, international students often have restrictions on how much and where they are allowed to work. Off-campus work is usually prohibited unless specific permissions are obtained and work hours during the semester are similarly restricted to 20 hours a week. ${ }^{7}$ Many external grants are restricted to U.S. citizens or residents, and university funding may be limited.

\section{Adjusting to a New Country and Academia}

The Systems. Some of the most difficult things to navigate in the U.S. are its healthcare and tax reporting systems. For those who come from countries with universally accessible healthcare, it takes a considerable amount of time (maybe even one or two disastrous hospital bills) to realize the extent of the system's complexity and irrationality, including details such as having to use in-network hospitals and having to set up a primary care doctor. Students will need to familiarize themselves with the premiums they need to pay for their insurance (although some department stipends come with this paid), their deductibles, out-of-pocket maximums, and what type of coverage they are receiving. For example, health insurance may not cover important costs such as vision or dental. Because of the large variation depending on the type of insurance and coverage students have, we recommend that students carefully check university websites and consult the staff to familiarize themselves with their insurances. Note that being insured may be a requirement for certain visas.

The tax reporting system is also convoluted and takes practice to figure out. How they should report certain funding, such as when international students come with a fellowship from their own country, is not straightforward. Whether they are residents for tax purposes also takes time to figure out. International student offices usually offer tax help, which especially first-time tax filers should take advantage of. However, even with that help, students should keep in mind that filing taxes is a tedious and time-consuming process, resulting in significant opportunity costs. Despite the difficulty navigating the U.S. tax system, there are certain tax treaties that international students can take advantage of that can save them a lot of money. While sometimes payroll staff recommends students not to take advantage of these because of additional paperwork, we recommend that students inform themselves to decide what fits their needs. ${ }^{8}$

Cultural Differences. Unless the students are from English-speaking countries, switching to an environment without the support of their native languages is hard in itself. But the supporters of international students must further understand that while the students have proven a sufficient grasp of the language to enter the Ph.D. program, some English expressions are still difficult to understand. Students from high-context cultures, where much communication is more implicit,

\footnotetext{
${ }^{7}$ For more detail, visit: https:/ /www.ice.gov/sevis/employment

${ }^{8}$ Tax treaties can be found here: https:/ / www.irs.gov / businesses/international-businesses/united-states-incometax-treaties-a-to-z
} 
may find themselves misunderstood or having difficulty expressing themselves. What the students choose to say may accidentally be culturally insensitive, but not intentionally. We believe the best course of action for international student supporters is to address this directly and privately with the student if such issues arise. As mentioned, culturally insensitive comments may just come from an unintended place and may just be a comment lost in translation.

Some other important cultural differences can manifest themselves in the following form. Some international students may not fully grasp that they should take the initiative in asking for meetings, advisor-advisee relationships, and opportunities in research/teaching assistance or coauthorships. Some may be used to waiting for formal announcements or outreach from the faculty and the department. Some may also be not used to speaking up in seminars and discussions. They may be afraid to set up meetings when progress is slow, not realizing that regular updates on projects and a discussion of the research bottleneck will be more helpful than radio silence. When faculty are not responsive to contacts, international students may not realize that they are allowed to send gentle reminders so that projects can move forward. They may not know what honorifics (if any) they should use to address the faculty and not understand that some faculty dislike formalities altogether. Again, the best course of action is to gently inform and guide the students on these cultural norms.

Limiting Beliefs About Academia. International students may have limiting beliefs on their abilities and places in academia. For example, as foreign nationals to the U.S., students may feel that they should focus on their regional expertise and shy away from majoring in American Politics or other concentrations in Comparative Politics. This is an understandable limiting belief, but it is not true. While international scholars may need more time and effort to build background knowledge, there are many excellent international scholars in all subfields. In fact, they may bring more diverse perspectives to the research agendas, expanding and enriching the scholarship. Therefore, students should not be afraid to explore and switch subfields as their interests change and evolve.

\section{Biases and Racism}

Another important aspect of adjusting to life as an international student is biases and racism. While some students are members of racial/ethnic majority groups in their country, they may find themselves minoritized in the U.S., leading to new experiences with racism, biases, and other stereotypes. Race/ethnicity, gender, and language can all affect students and their experiences, both inside and outside the campus, making not only degree progression difficult but may also significantly affect students' mental health (Wei et al., 2015).

Over recent years, many discriminatory incidents have been highlighted in the media, such as faculty members at Duke advising Chinese students not to speak Chinese in the building, with 
some even wanting to use speaking their own language against the students in internships and funding decisions. Similarly, a professor at the University of Houston wrote an email to students about body odor, singling out and targeting specific countries and cultures in the process.

While certain incidents of racism and discrimination are specific to international students (Lee and Rice, 2007; Poyrazli and Lopez, 2007; Smith and Khawaja, 2011), biases affecting domestic students can also affect international students. For example, issues such as sexual harassment, as highlighted by \#MeToo PoliSci among others, are realities that many students experience. This can particularly affect some international students. For example, Asian women continue to be exoticized and fetishized (Sue et al., 2009; Ho et al., 2018), and coupled with how some Asian students are less likely to identify behaviors usually categorized as sexual harassment as such (Tang et al., 1996; Ho et al., 2018), this leaves some students particularly vulnerable.

Although fixing these issues is not the responsibility of those experiencing them, joining student organizations such as groups for international students or students from their country may help students find their support network. Establishing a strong support network within the department, if possible, can only improve students' quality of life. Supporters of international students need to be aware of how racism, sexism, and other biases inhibit and affect students' studies and success. There is also ample research highlighting the detrimental effects of discrimination on mental health (Sümer et al., 2008). Discriminatory practices within and outside of departments should not be tolerated and need to be adequately addressed by administrators, staff, and faculty to ensure the safety and well-being of students.

\section{What Can Supporters of International Students Do?}

There are some steps that faculty mentors and the university administration can take to support international students.

Assess the International Student Program. The well-being and success of international students rely heavily on the capacity, expertise, and accessibility of the university's International Student Program (or something equivalent). They contain, in ICE's terminology, Designated School Officials (DSOs). Not only do they provide legal guidance in conjunction with the Office of the General Counsel on the immigration laws, but they also sign necessary documentation for travel (the I-20) and advise students on their rights, responsibilities, and other potential issues. Given this, there must be a well-functioning international student program at the institutional level. Regular discourse with students on the system's efficacy will be highly beneficial.

The program often shoulders more than simply the required paperwork and decoding changes in immigration rules. It typically provides workshops and guides on the aforementioned hidden costs and barriers, such as tax workshops for nonresidents or community conversations on racism, in conjunction with departments that oversee diversity, equity, and inclusion. A dialogue 
with the students on what other potential areas they would want to know more about-such as an immigration roadmap on the OPT process and the H-1B visa, which the students should know about-would also be greatly helpful.

Provide Financial Support. Offering plenty of financial resources that international students can access is crucial for retention and degree completion. In particular, a small, no-interest new graduate student loan to international students at the beginning of their program will be of much help. If there are external funding opportunities open to those without U.S. citizenship, encourage the students to apply and guide them through the process. This is particularly important because many scholarships in the U.S. are restricted to U.S. citizens or permanent residents, making many international students ineligible.

Foster Support Networks. Another easy step is providing opportunities for international students to socialize and form a support network so that they can make psychological adjustments (Sümer et al., 2008; Bender et al., 2019). These can include international student orientations, low-stake meet and greet coffees, and encouragement to join affinity groups in conferences or specific-country student organizations.

Be Mindful of Travel Time Commitments. Advisors would want to be mindful of the fact that international travels to home can take up to a month and that break from work is to be expected during this period. The tasks that students must perform back home are numerous, ranging from visa renewals to sorting out tax documents between two countries. What's more, this is their chance to see their family and friends that they cannot easily visit. Please extend kindness and offer days off work for these opportunities.

Be Informed and Observant. There are many rules that international students need to abide by to maintain their legal status in the U.S. Work restrictions, including limited hours of work during the semester and semester breaks ${ }^{9}$ and limitations on the type of work and locations. Advisors and departments should be aware of these limitations (and the aforementioned need for financial support) and try their best to support them.

We also suggest that the supporters observe the students closely and check in with them regularly to see if they need more resources. For example, some international students may need encouragement and confidence-building in seminar participation, paper discussions, subfield selection, teaching, and voicing their own opinion in general. Some may benefit from taking English as a second language (ESL) classes or working with the Writing Center to develop academic writing skills. Others may need more training or guidance on how to be a teaching assistant in

\footnotetext{
${ }^{9}$ See the ICE website for information on employment as an F-1 student or consult your university's international student office for information that is correct for your case.
} 
a U.S. classroom (Okura, 2006). Such mentoring will greatly enhance the students' psychological adjustment (Zhang and Goodson, 2011) and chances of success.

\section{How Can International Students Better Prepare Themselves?}

Be Realistic about the Costs. Calculate the cost that it will take to live in your university's town. Keep in mind that the cost of living that the university suggests may be lower than what you need. Furthermore, as mentioned above, be prepared that there may be a large upfront cost you have to cover (i.e., moving expenses, security deposits, etc.) before you receive your first paycheck. Discuss your funding and living expenses with your advisor and the department, subject to the legal requirements.

Understand Your International Student Program. Take time to figure out the administrative structure of the international student program at your university. Make sure to know who your DSOs are and what steps you need to take to (1) work with them on getting the documents in order and (2) consult them when situations arise that call for their help. For example, if your school takes two weeks or more to sign the I-20, you will want to ensure that the signatures are frequently updated just in case, or be aware of alternative steps in case you have to leave the U.S. on an emergency trip without your I-20. Make sure to be subscribed to their events to fully utilize the unique resources they may have designed for international students.

Communicate With Existing Students and Join Support Groups. Most graduate students are happy to talk with prospective students about their department and university. These students can be your best resources in helping you navigate living in your town, in assessing the department climate and whether you think it will be a good fit for you, ${ }^{10}$ about the cost of living in your university's area, and faculty-student relations. If there are other international students in your prospective department-even better if you can find affinity groups based on citizenship or coethnicity! - talk to them about their experience as international students. They will be a crucial resource in helping you navigate the specific challenges of being an international student.

Align Expectations With the Faculty. As shown above, expectations in a U.S. graduate program may involve substantially different cultural norms, such as the degree of autonomy or taking the initiative. Take the initiative in communicating with your advisors and mentors to revisit subtle assumptions you may have, such as the intervals you are expected to meet with faculty or how much progress is expected at various stages of the degree. Having open conversations about aligning expectations early in the degree can go a long way.

\footnotetext{
${ }^{10}$ Note, however, that these should always be taken with a grain of salt, as even existing students can have wrong information based on rumors.
} 
Speak Out About Your Needs. Sometimes, the key figures in your Ph.D. journey, such as advisors, department heads, or fellow students who are U.S. citizens, may not fully realize your unique needs as international students. It could be tremendously helpful to foster conversationsalthough neither easy nor universally recommended-about what you might need and how that might break through the hidden costs and barriers. It is okay to ask for help, as long as you show appreciation when you receive the help you need.

Of course, the reality is that sometimes these figures may not be the most helpful or supportive. We recommend international students broaden their network and also connect with faculty and students from other institutions (Kim et al., 2021). Academic conferences, ${ }^{11}$ academic Twitter, or even emailing faculty or students whose work you admire are great places to start fostering connections, including, but not limited to, other international scholars who can be your mentors, colleagues, and friends.

\section{Concluding Thoughts}

Although many of the costs and barriers that international graduate students may make studying abroad sound discouraging, we also want to highlight the benefits of taking the leap and going to graduate school in a different country. Both authors of this paper are or were international students in the United States at some point and can attest that being immersed in a different cultural and academic context has been intellectually stimulating and academically beneficial. We believe that it has made us stronger and more well-rounded academics as well.

We hope that this paper illuminates some challenges that students often face or are insufficiently informed on before they come to the United States so that they can come prepared and know full well what they will be getting themselves into. Furthermore, we hope that institutions that host international graduate students support their students who contribute to the intellectual and cultural diversity of their departments.

\section{References}

Bender, Michael, Yvette van Osch, Willem Sleegers, and Mengyu Ye (2019). Social Support Benefits Psychological Adjustment of International Students: Evidence From a Meta-Analysis. Journal of Cross-Cultural Psychology 50(7), 827-847.

Ho, Ivy K, Khanh T Dinh, Sarah M Bellefontaine, and Amanda L Irving (2018). Cultural adaptation and sexual harassment in the lives of Asian American women. Women E Therapy 41(3-4), 281-297.

\footnotetext{
${ }^{11}$ Large conferences like APSA usually attract many people from all over the country and the world. Smaller field-specific conferences such as APOSS may be easier and less intimidating to make connections.
} 
Kim, Seo-young Silvia, Hannah Lebovits, and Sarah Shugars (2021). Networking 101 for Graduate Students: Building a Bigger Table. PS: Political Science E Politics, 1-6.

Lee, Jenny J. and Charles Rice (2007). Welcome to America? International student perceptions of discrimination. Higher Education 53(3), 381-409.

Okura, Masako Rachel (2006). Reflections on the APSA Report on Graduate Education: International Students and Their Teacher Training. PS: Political Science E Politics 39(2), 311-315. Publisher: Cambridge University Press.

Poyrazli, Senel and Marcos Damian Lopez (2007). An Exploratory Study of Perceived Discrimination and Homesickness: A Comparison of International Students and American Students. The Journal of Psychology 141(3), 263-280.

Smith, Rachel A. and Nigar G. Khawaja (2011). A review of the acculturation experiences of international students. International Journal of Intercultural Relations 35(6), 699-713.

Sue, Derald Wing, Jennifer Bucceri, Annie I Lin, Kevin L Nadal, and Gina C Torino (2009). Racial microaggressions and the Asian american experience. Asian American Journal of Psychology S(1), 88-101.

Sümer, Seda, Senel Poyrazli, and Kamini Grahame (2008). Predictors of Depression and Anxiety Among International Students. Journal of Counseling $\mathcal{E}$ Development 86(4), 429-437.

Tang, Catherine So-kum, Michelle SM Yik, Fanny MC Cheung, Po-king Choi, and Kit-chun Au (1996). Sexual harassment of Chinese college students. Archives of sexual behavior 25(2), 201-215.

Wei, Meifen, Ya-Shu Liang, Yi Du, Raquel Botello, and Chun-I Li (2015). Moderating effects of perceived language discrimination on mental health outcomes among Chinese international students. Asian American Journal of Psychology 6(3), 213-222.

Zhang, Jing and Patricia Goodson (2011). Predictors of international students' psychosocial adjustment to life in the United States: A systematic review. International Journal of Intercultural Relations 35(2), 139-162. 